\title{
Persistent Sodium Currents Participate in Fictive Locomotion Generation in Neonatal Mouse Spinal Cord
}

\author{
Guisheng Zhong, Mark A. Masino, and Ronald M. Harris-Warrick \\ Department of Neurobiology and Behavior, Cornell University, Ithaca, New York 14853
}

\begin{abstract}
The persistent sodium current $\left(I_{\mathrm{Na}(\mathrm{P})}\right)$ has been implicated in the regulation of synaptic integration, intrinsic membrane properties, and rhythm generation in many types of neurons. We characterized $I_{\mathrm{Na}(\mathrm{P})}$ in commissural interneurons (CINs) in the neonatal (postnatal days 0 -3) mouse spinal cord; it is activated at subthreshold potentials, inactivates slowly, and can be blocked by low concentrations of riluzole. The role of $I_{\mathrm{Na}(\mathrm{P})}$ in locomotor pattern generation was examined by applying riluzole during fictive locomotion induced by NMDA, serotonin, and dopamine or by stimulation of the cauda equina. Blockade of $I_{\mathrm{Na}(\mathrm{P})}$ has marginal effects on the locomotion frequency but progressively weakens the rhythmic firing and locomotor-related membrane oscillation of CINs and motoneurons (MNs) and the locomotor-like bursts in ventral roots, until the motor pattern ceases. Riluzole directly affects the intrinsic firing properties of CINs and MNs, reducing their ability to fire repetitively during tonic depolarizations and raising their spike threshold. At the same time, riluzole has little effects on the strength of spike-evoked synaptic transmission onto CINs and MNs. Our results suggest that $I_{\mathrm{Na}(\mathrm{P})}$ is essential for the generation of the locomotor pattern and acts in part by regulating the frequency of interneuron firing in the central pattern generator for locomotion.
\end{abstract}

Key words: mouse; persistent sodium current; riluzole; locomotion; NMDA; spinal cord

\section{Introduction}

The neural circuit generating coordinated locomotor patterns can be activated in the isolated vertebrate spinal cord (Kudo and Yamada, 1987; Cazalets et al., 1992, 1995; Kjaerulff and Kiehn, 1996; Cowley and Schmidt, 1997; Kiehn and Kjaerulff, 1998). In recent work, the isolated neonatal rodent spinal cord has proven to be an excellent preparation to investigate the neural circuit underlying locomotion. Using genetic and anatomical labeling methods, a number of neuronal types have been implicated in the generation of the locomotor pattern (Butt et al., 2002; Butt and Kiehn, 2003; Kullander et al., 2003; Lanuza et al., 2004; Butt et al., 2005; Hinckley et al., 2005; Wilson et al., 2005; Gosgnach et al., 2006; Nishimaru et al., 2006). However, our understanding of the roles of these neurons in the network remains incomplete.

Research on motor networks from simpler invertebrates has shown that a full understanding of a neural network requires not only identifying the major classes of neurons in the network and their synaptic interactions but also understanding the intrinsic electrophysiological properties of the component neurons (Harris-Warrick and Marder, 1991; Marder and Calabrese, 1996; Kiehn and Kjaerulff, 1998). Multiple types of ion channels regulate the intrinsic membrane properties of neurons and their synaptic integration, thus affecting the operation of the network. To

Received Jan. 11, 2007; revised Feb. 19, 2007; accepted Feb. 20, 2007

This work was supported by National Institutes of Health Grants R01-NS35631 (R.M.H.-W.) and R01-NS050943 (J. Guckenheimer). We thank Dr. Bruce Johnson for helpful comments on this manuscript.

Correspondence should be addressed to Guisheng Zhong, Department of Neurobiology and Behavior, Cornell University, Seeley G. Mudd Hall, Ithaca, NY 14853. E-mail: gz33@cornell.edu.

DOI:10.1523/JNEUROSCI.0124-07.2007

Copyright $\odot 2007$ Society for Neuroscience $\quad$ 0270-6474/07/274507-12\$15.00/0 understand how neural circuits function and control behavior requires knowledge about the role of different ion channels in the neural network (Harris-Warrick, 2002). This question has been studied in a variety of vertebrate (El Manira et al., 1994; Buschges et al., 2000; Hess and El Manira, 2001; Wang et al., 2006) and invertebrate (Harris-Warrick et al., 1995, 1998; Zhang et al., 2003) preparations. However, there is little information about the role of ion channels in the generation of fictive locomotion in neonatal mouse spinal cord.

In this study, we investigated the role of the persistent sodium current $\left(I_{\mathrm{Na}(\mathrm{P})}\right)$ in the production of fictive locomotion in the isolated neonatal mouse spinal cord. $I_{\mathrm{Na}(\mathrm{P})}$ is involved in many types of neural rhythm generation (Crill, 1996; Del Negro et al., 2002, 2005; Darbon et al., 2004; Paton et al., 2006; Van Drongelen et al., 2006). Fictive locomotion can be evoked in neonatal spinal cords with a combination of NMDA, serotonin (5-HT), and dopamine (DA) (Jiang et al., 1999; Hinckley et al., 2005; Juvin et al., 2005) or by stimulation of the cauda equina (Whelan et al., 2000; Gordon and Whelan, 2006). We characterized $I_{\mathrm{Na}(\mathrm{P})}$ in commissural interneurons (CINs) and used a relatively selective pharmacological blocker, riluzole, to investigate its role in shaping the intrinsic membrane properties of CINs and motoneurons (MNs) and in rhythmic locomotor pattern generation. We show that, at low concentration $(5 \mu \mathrm{M})$, riluzole inhibits most of the $I_{\mathrm{Na}(\mathrm{P})}$ in CINs; this blocks these neurons from firing tonically to depolarizing voltage steps and depolarizes the threshold for spike initiation in CINs and MNs. In the intact spinal cord, riluzole progressively weakens the strength of rhythmic membrane potential oscillations in CINs and MNs and rhythmic ventral root bursting during fictive locomotion, eventually blocking the rhythmic motor output. 


\section{Materials and Methods}

Whole-cord preparations. Experiments were performed using spinal cords of postnatal day (P0) to P3 ICR mice (Taconic, Hudson, NY). The animal protocol was approved by the Institutional Animal Care and Use Committee at Cornell University and was in accordance with National Institutes of Health guidelines. Animals were killed by decapitation, and their spinal cords from segment C5 to S3 were ventrally dissected and isolated under ice-cold $\left(4^{\circ} \mathrm{C}\right)$ oxygenated $\left(95 \% \mathrm{O}_{2} / 5 \% \mathrm{CO}_{2}\right)$ low-calcium Ringer's solution (in mM: $111 \mathrm{NaCl}, 3.08 \mathrm{KCl}, 25 \mathrm{NaHCO}_{3}, 1.18$ $\mathrm{KH}_{2} \mathrm{PO}_{4}, 3.25 \mathrm{MgSO}_{4}, 0.25 \mathrm{CaCl}_{2}$, and $11 \mathrm{D}$-glucose). The spinal cord was pinned ventral side up and superfused with oxygenated normal Ringer's solution (in mM: $111 \mathrm{NaCl}, 3.08 \mathrm{KCl}, 25 \mathrm{NaHCO}_{3}, 1.18$ $\mathrm{KH}_{2} \mathrm{PO}_{4}, 1.25 \mathrm{MgSO}_{4}, 2.52 \mathrm{CaCl}_{2}$, and $11 \mathrm{D}$-glucose) for $1 \mathrm{~h}$ at room temperature $\left(20-22^{\circ} \mathrm{C}\right)$ before starting the experiment.

To identify the CINs in the intact spinal cord, the hemicord was slit along the midline rostrally between T13 and L1 and caudally between L4 and L5 for several segments before performing a contralateral transverse hemisection, thus liberating short lengths of contralateral hemicords several segments rostral and caudal of the recording site (see Fig. $1 \mathrm{~A}$ ). These hemicords were sucked into stimulation electrodes, and brief current pulses were delivered to stimulate axons that were contralateral and rostral or caudal to the recorded neuron. CINs were identified by a collision test, in which orthodromic action potentials evoked by current injection in the soma collided with and eliminated appropriately timed antidromic action potentials evoked by stimulation of the contralateral hemicord (Butt et al., 2002; Zhong et al., 2006a,b). To identify MNs, a suction electrode was used to stimulate the ipsilateral L2 ventral root. MNs were identified by the antidromic action potential evoked by ventral root stimulation and verified by a collision test, in which orthodromic action potentials evoked by current injection in the soma collided with appropriately timed antidromic action potentials from the root.

Locomotor-like activity was reliably evoked in the intact spinal cord by bath superfusion with Ringer's solution containing a combination of NMDA $(3-10 \mu \mathrm{M}), 5-\mathrm{HT}(6-12 \mu \mathrm{M})$, and DA (15-20 $\mu \mathrm{M})$. Recordings were made with suction electrodes on one to three ventral roots [typically the left (1L2) and right L2 (rL2) (primarily flexor-related) and the left L5 (IL5) (extensor related) nerves] to characterize the locomotor-like activity. In some experiments, the caudal end of the spinal cord was dissected and locomotor-like activity was reliably induced by stimulating the cauda equina (Whelan et al., 2000; Gordon and Whelan, 2006). Constant current stimulus trains $(0.1-1 \mathrm{~mA}, 2-2.5 \mathrm{~Hz}$ for $15 \mathrm{~s})$ were delivered to coccygeal roots through a suction electrode no more frequently than once every 3 min throughout an experiment. Ventral root recordings were bandpass filtered ( $100 \mathrm{~Hz}$ to $1 \mathrm{kHz})$ and recorded using an alternating current amplifier (model 1600; A-M Systems, Carlsborg, WA).

Slice preparations. Neonatal spinal cords ( $\mathrm{P} 0-\mathrm{P} 3)$ were isolated in lowcalcium Ringer's solution. CINs were labeled retrogradely by making fine slits in the contralateral hemicord rostrally (T13-L1) and caudally (L4L5) to the L1-L2 region and applying crystals of fluorescent dextran amines [3000 molecular weight Texas Red dextran amine, and 3000 molecular weight fluorescein dextran amine (Invitrogen, Carlsbad, CA)] to the slits, as described previously (Eide et al., 1999; Butt et al., 2002; Carlin et al., 2006; Zhong et al., 2006a). The spinal cord was incubated in oxygenated mouse Ringer's solution at $30^{\circ} \mathrm{C}$ for $\sim 1$ h to let the dyes transport to CIN somata. Transverse spinal cord slices $(300 \mu \mathrm{m})$ were made with a vibrating microtome (Leica, Nussloch, Germany) and transferred to regular mouse Ringer's solution at $30^{\circ} \mathrm{C}$ for $1 \mathrm{~h}$ before recording at room temperature $\left(20-23^{\circ} \mathrm{C}\right)$ with perfusion $(\sim 3 \mathrm{ml} / \mathrm{min})$ of mouse Ringer's solution.

Patch-clamp recording. To make whole-cell recordings from the L2 segment of the intact cord preparation, a patch electrode pulled from thick-wall borosilicate glass (World Precision Instruments, Sarasota, FL) on a vertical puller (Narishige, Tokyo, Japan) with resistances of 6-10 $\mathrm{M} \Omega$ was lowered into a small slit in the ventromedial surface of the L2 segment. The pipette solution contained the following (in $\mathrm{mM}$ ): 138 K-gluconate, 10 HEPES, 5 ATP-Mg, 0.3 GTP-Li, and $0.0001 \mathrm{CaCl}_{2}, \mathrm{pH}$ 7.4 with $\mathrm{KOH}$. The seal resistance obtained before recordings was always $>1 \mathrm{G} \Omega$. Blind patch-clamp recordings were made with a Multiclamp
700A amplifier (Molecular Devices, Palo Alto, CA) and were driven by Clampex (pClamp 9; Molecular Devices).

To make whole-cell recordings from spinal cord slices, fluoresceinand Texas Red-labeled neurons contralateral to the dye injection sites were identified under epifluorescent illumination and visualized using differential interference contrast optics (Axioskop 2FS plus; Zeiss, Thornwood, NY). To record $I_{\mathrm{Na}(\mathrm{P})}$ from CINs, electrodes with 3-6 M $\Omega$ resistance were used. The extracellular solution for $I_{\mathrm{Na}(\mathrm{P})}$ measurements contained the following (in mM): $111 \mathrm{NaCl}, 3.08 \mathrm{KCl}, 2 \mathrm{CaCl}_{2}, 2 \mathrm{MgCl}_{2}$, 10 glucose, 10 tetraethylammonium chloride (TEA), 4 4-aminopyridine (4-AP), $0.5 \mathrm{CdCl}_{2}$, and $10 \mathrm{HEPES}, \mathrm{pH}$ 7.3. The pipette solution for these measurements contained the following (in mM): $120 \mathrm{CsCl}$, 10 HEPES, 5 ATP-Mg, 0.3 GTP-Li, and 0.0001 $\mathrm{CaCl}_{2}$, pH 7.33. $I_{\mathrm{Na}(\mathrm{P})}$ was recorded after at least 5 min perfusion of extracellular blockers, when a satisfactory block of both $\mathrm{K}^{+}$and $\mathrm{Ca}^{2+}$ currents was achieved. During voltageclamp recording, the access resistance was monitored continually. The recordings were discarded if the access resistance changed $>10 \%$ during the experiment. The liquid junction potential of the electrode was measured and was corrected off-line. Data were filtered at $10 \mathrm{kHz}$ and digitized at $20 \mathrm{kHz}$.

Data analysis. Locomotor-like activity was recorded in the intact spinal cord preparation during bath application of NMDA, 5-HT, and DA. Clampfit 9.0, Excel (Microsoft, Seattle, WA), and Spike 2 (Cambridge Electronic Design, Cambridge, UK) were used for data analysis. Because the duty cycle of the ventral root bursts sometimes varied, a double normalization process was used to analyze the phasing of neural activity during the locomotor cycle (Berkowitz and Stein, 1994; Zhong et al., 2006a,b). A cycle of fictive locomotion started with the onset of an L2 ventral root burst ipsilateral to the whole-cell recording site (iL2) and ended at the onset of the next iL2 burst; these onsets were determined by a custom-made program in Spike 2 to detect when the rectified signal exceeded the average noise level between bursts by a preset value. Circular statistics were used to determine the significance of the phasing of CIN or MN firing during fictive locomotion (Kjaerulff and Kiehn, 1996; Zar, 2000). The latency to each CIN or MN spike was measured relative to the beginning of iL2 ventral root burst. The mean latency was calculated as described by Kjaerulff and Kiehn (1996). The direction of a vector represents the average preferred phase of the neuronal firing, whereas its length, $r$, is a measure of statistical significance of the preferred phase. Vectors with a phase in the range of $0.0-0.5$ corresponded to cells firing in-phase with iL2 root activity. $p$ values for the significance of $r$ were calculated as described by Kjaerulff and Kiehn (1996) and Zar (2000).

Drugs. D(-)-2-amino-5-phosphonopentanoic acid (AP-5), 6-cyano7-nitroquinoxaline-2,3-dione disodium salt (CNQX), strychnine, picrotoxin, riluzole, NMDA, and 5-HT were purchased from Sigma (St. Louis, $\mathrm{MO}$ ). Stock solutions of riluzole were made in dimethylsulfoxide (DMSO) and diluted in the extracellular solution; the final DMSO concentration in extracellular solution was $0.05 \%$ for $5 \mu \mathrm{M}$ riluzole. Other drugs were dissolved in Ringer's solution and bath applied to the preparation.

Data are shown as means $\pm \mathrm{SD}$ ( $n=$ number of cells). Significance of differences $(p<0.05)$ was assessed using Student's $t$ test or one-way ANOVA.

\section{Results}

Identification of CINs and MNs in whole-cord preparations

Whole-cord preparations from neonatal mice (P0-P3) were used in this series of experiments. To monitor fictive locomotion evoked by a combination of NMDA, 5-HT, and DA, three suction electrodes were used to monitor the left L2 (IL2), left L5 (IL5), and right L2 (rL2) ventral root activity; the motor pattern is characterized by left-right alternation and ipsilateral flexor-extensor alternation (Fig. $1 \mathrm{Bi}$ ). We generated circular plots of the relative phasing of the left and right ventral root bursts and the ipsilateral flexor and extensor ventral roots (Fig. 1 Bii,Biii): as can be seen, both are tightly clustered around 0.5 (left-right, $0.51 \pm 0.04$; flexor-extensor, $0.49 \pm 0.04$ ).

During fictive locomotion, activities of single identified neu- 


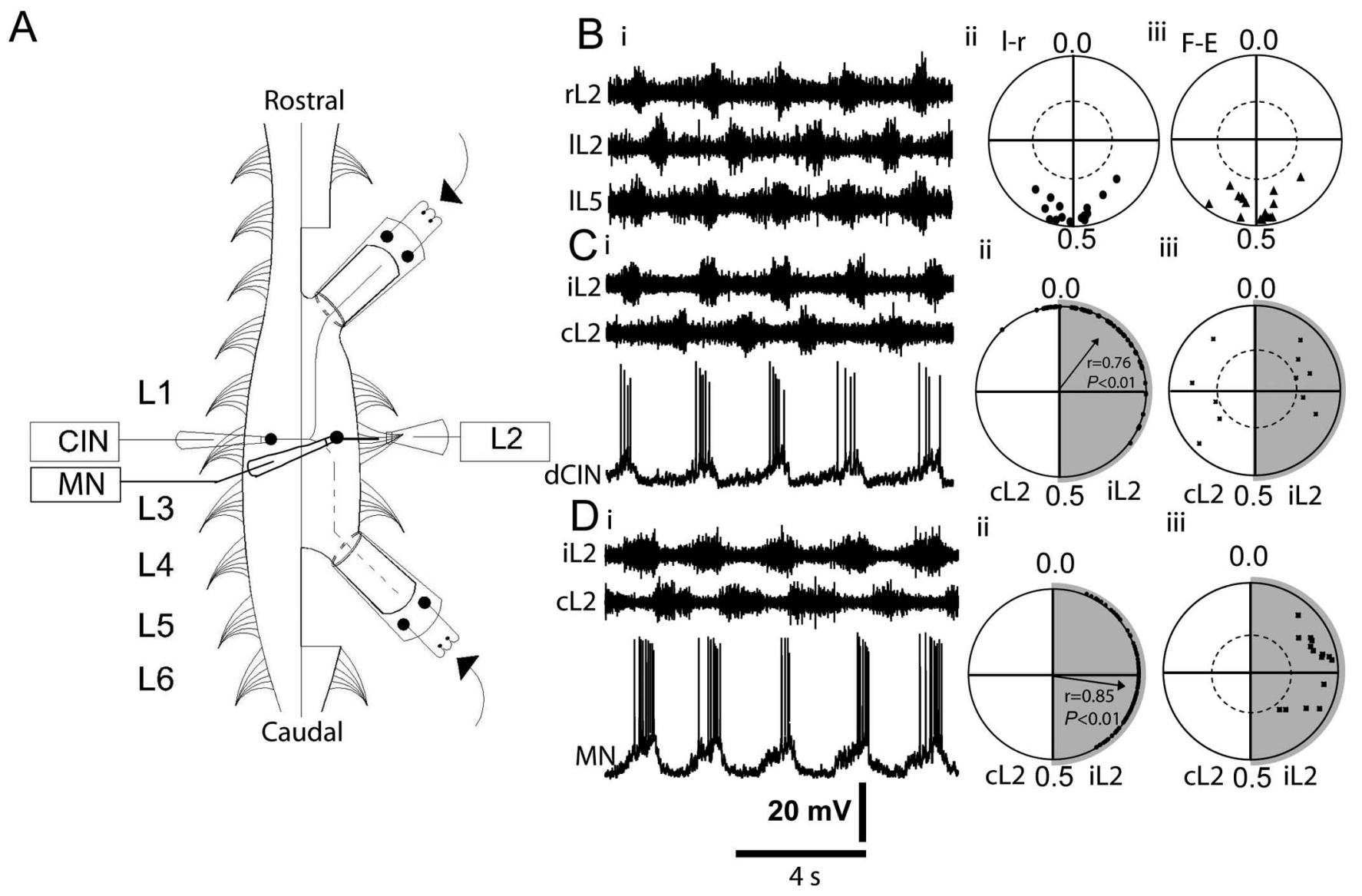

Figure 1. Experimental setup. A, Stimulation suction electrodes were placed on the rostral and caudal contralateral hemicords at the level of T13-L1 and L4-L5, respectively, to stimulate the contralateral projecting axons of CINs. Additionally, three suction recording electrodes were placed to monitor nerve activities from IL2, rL2, and IL5. A patch-clamp electrode was inserted in a small slit made in the L2 segment for neuronal recording. Bi, Extracellular recordings from IL2, rL2, and IL5 ventral roots after application of $6 \mu \mathrm{M}$ NMDA, $12 \mu \mathrm{M} 5-\mathrm{HT}$, and $18 \mu \mathrm{M}$ DA, showing locomotor-like activity characterized by left-right (Bii) and flexor- extensor (Biii) alternation in a P2 spinal cord. The dotted circle indicates the level of statistical significance ( $p<0.05)$. Ci, Di, A typical firing pattern of a dCIN and an MN during NMDA, 5-HT, and DA-induced locomotor-like activity. Cii, Dii, Circular lots of the phase and rhythmicity of the dCIN and MN from Ci and Di derived from circular statistics. Each black circle represents one action potential. The open square is the average phase vector point for this neuron. The direction of the vector represents the preferred phase of firing of the neuron, and the distance from the center indicates the statistical significance of the rhythmicity of the neuron. Circular plots are read in a clockwise direction with 0 at the $12 o^{\prime}$ clock position. Ciii, Diii, Pooled data from the circular analysis showing the distribution of the preferred firing phase of all rhythmically active CINs and MNs. The dotted circle indicates the level of statistical significance $(p<0.05)$. Each small square represents the vector point for one experiment. Gray-shaded areas represent the ipsilateral L2 flexor phase. I-r, Left-right; F-E, flexor- extensor; $C$, contralateral.

rons can be monitored by whole-cell patch recordings in the isolated spinal cord preparation. CINs were identified after blind patching by collision tests of their orthodromic action potentials with antidromic action potentials evoked by stimulation of the contralateral rostral [ascending CIN (aCIN)] or caudal [descending CIN (dCIN)] hemicord (Zhong et al., 2006a,b). Figure $1 \mathrm{~A}$ shows the experimental setup for identification of the CIN and $\mathrm{MN}$, and $\mathrm{C} i$ shows one example of the firing pattern and phase of a dCIN during fictive locomotion. We also generated circular plots of the phase of each action potential relative to the iL2 (gray) and CL2 (white) burst phases (Fig. 1Cii). This CIN was active at the end of the CL2 burst and peaked in activity during the beginning of the iL2 burst. This can be seen by the point inside the circle indicating the vector of peak activity (Fig. 1Cii); the distance from the center of the circle reflects the statistical significance of the rhythmic bursting of the neuron. Figure 1Ciii shows the phasing and rhythmicity of 11 different CINs, which demonstrates that these interneurons were active at all different phases during the cycle (Butt et al., 2002; Zhong et al., 2006a,b).

MNs, which are the final common output from the locomotor central pattern generator (CPG), provide a record of the synaptic drive from the CPG. To record from an MN, blind patching was made through a slit in the ventrolateral spinal cord (Fig. 1A). MNs were identified by a collision test of their orthodromic action potentials with antidromic spikes evoked by ventral root stimulation. To further confirm the MN recording, sulforhodamine $\mathrm{B}$ acid chloride was included in the patch solution in five experiments. In all of these experiments, two-photon laserscanning microscopy of the red fluorescence showed the axon of the MN in the ventral L2 root (data not shown). Figure 1 Di shows a typical recording from an $\mathrm{MN}$ during fictive locomotion; as expected, this $\mathrm{MN}$, and all MNs that we recorded, oscillated inphase with the iL2 ventral root discharge. The phase of peak activity of this neuron is shown inside the circle of Figure 1 Dii. The circular plot of peak action potential phase for $16 \mathrm{MNs}$ (Fig. 1 Diii) shows that all of the MNs are firing in-phase with the iL2 (gray) ventral root burst.

Effects of riluzole on $I_{\mathrm{Na}(\mathrm{P})}$ in CINs

We first determined the concentration of riluzole needed to block $I_{\mathrm{Na}(\mathrm{P})}$ in neonatal spinal cord slices. To improve the voltage clamp and minimize the effects of potassium and calcium currents, 10 


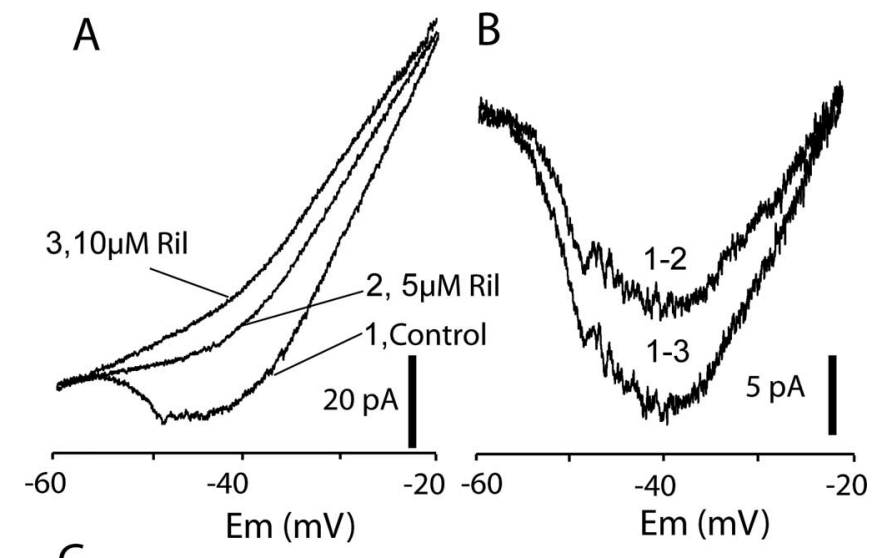

C

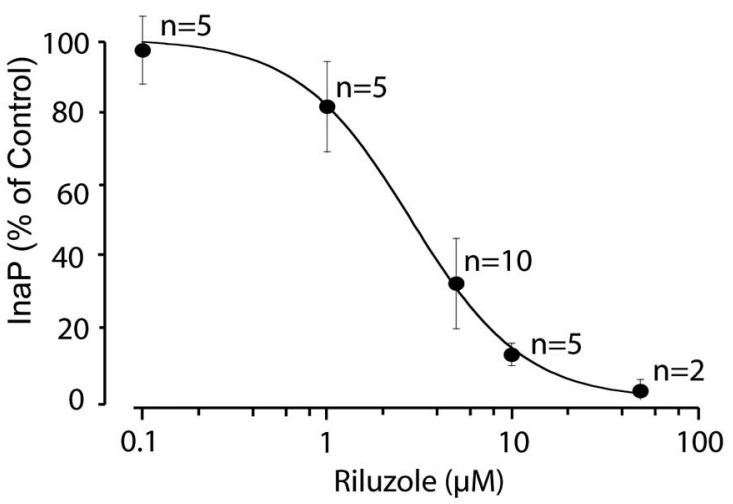

Figure 2. Riluzole blocks $I_{\mathrm{Na}(\mathrm{P})}$ in $\mathrm{CINs.} A, I_{\mathrm{Na}(\mathrm{P})}$ recordings by a ramp protocol from -90 to 10 $\mathrm{mV}$ at the rate of $20 \mathrm{mV} / \mathrm{s}$ from a dCIN in control and different concentrations of riluzole (Ril). $\boldsymbol{B}$, Riluzole-sensitive inward currents. $C$, Dose-response curve showing the effects of riluzole on $I_{\mathrm{Na}(\mathrm{P})}$. The curve was fit with the equation $1 /\left(1+\left(\left([D] / \mathrm{C}_{50}\right)^{n}\right)\right.$, where $[D]$ is the riluzole concentration, $I_{50}$ is the dose for half-inhibition, and $n$ is the Hill coefficient. $I_{50}$ of $2.8 \pm 0.2 \mu \mathrm{m}$.

mM TEA, $4 \mathrm{~mm} 4$-AP, and $500 \mu \mathrm{M} \mathrm{CdCl}_{2}$ were added to the extracellular solution, and $\mathrm{K}$-gluconate was replaced by $\mathrm{CsCl}$ in the electrode solution. Using a ramp protocol from -90 to $10 \mathrm{mV}$ at the rate of $20 \mathrm{mV} / \mathrm{s}$, we recorded $I_{\mathrm{Na} \text { (P) }}$ from 10 CINs including four dCINs and six aCINs in slice preparations; the CINs were identified in the slices by retrograde labeling with crystals of fluorescent dextran amines (Texas Red and fluorescein dextran amines) from slits in the contralateral rostral or caudal hemicord. $I_{\mathrm{Na}(\mathrm{P})}$, measured by the subtraction of the control from the trace with riluzole or TTX application, was activated at $-54 \pm 3 \mathrm{mV}$ and reached maximum amplitude during the voltage ramp at $-41 \pm 4 \mathrm{mV}$ (Fig. $2 A, B$ ). The amplitude of $I_{\mathrm{Na}(\mathrm{P})}$ was calculated from the reduction of the peak inward current, which can be blocked by $1 \mu \mathrm{M}$ TTX or saturating riluzole, and varied from 15 to $65 \mathrm{pA}(32 \pm 6 \mathrm{pA} ; n=10)$. In control experiments, DMSO (from 0.01 to $0.1 \%$ ) had no significant effects on the amplitude of $I_{\mathrm{Na}(\mathrm{P})}$.

To determine the concentration dependence of riluzole block of $I_{\mathrm{Na}(\mathrm{P})}$ in neonatal spinal cord slices, different doses of riluzole from 0.1 to $50 \mu \mathrm{M}$ were superfused until steady-state block was achieved. We found that riluzole starts to reduce the amplitude of $I_{\mathrm{Na}(\mathrm{P})}$ at $1 \mu \mathrm{M}$. At $5 \mu \mathrm{M}$, riluzole reduces the peak inward current by $66 \%$ in both aCINs and dCINs; these neurons showed no obvious differences in their riluzole sensitivity, so we pooled together their data (Fig. 2C). Figure $2 A$ shows the effects of 5 and 10 $\mu \mathrm{M}$ riluzole on the amplitude of $I_{\mathrm{Na}(\mathrm{P})}$ in a dCIN. Figure $2 B$ is the riluzole-sensitive inward current, obtained by subtracting the riluzole-blocked current from the control current. Riluzole had no detectable effect on the voltage sensitivity of $I_{\mathrm{Na}(\mathrm{P})}$ and just reduced the peak amplitude of the inward current. Figure $2 C$ shows the concentration dependence of riluzole block of $I_{\mathrm{Na}(\mathrm{P})}$ $\left(p<0.01\right.$, one-way ANOVA); the $\mathrm{IC}_{50}$ is $2.8 \mu \mathrm{M}$. Because it reduced $I_{\mathrm{Na} \text { (P) }}$ by approximately two-thirds, we choose to use 5 $\mu \mathrm{M}$ riluzole for the rest of our experiments.

\section{Effects of riluzole on fictive locomotion}

To monitor fictive locomotion, we applied a combination of NMDA, 5-HT, and DA to the whole-cord preparation, and L2 and L5 ventral root activities were recorded using suction electrodes (Fig. $3 A$ ). In control experiments, $0.05 \%$ DMSO had no effect on fictive locomotion up to $1 \mathrm{~h}(n=5)$. Bath application of $5 \mu \mathrm{M}$ riluzole reversibly blocked fictive locomotion after $20-40$ min of application $(n=50)$ (Fig. $3 A$ ). The locomotor burst amplitude, calculated from the integrated ventral root trace, started to decrease rapidly after $10-15 \mathrm{~min}$ and progressively decreased until it completely disappeared after 30-40 min (Fig. 3C). Interestingly, if the initial frequency was relatively low $(<0.25 \mathrm{~Hz})$ there was almost no effect of riluzole on the cycle frequency during the time the motor pattern was getting weaker (Fig. $3 \mathrm{~A}, \mathrm{C}$ ) (control, $0.21 \pm 0.03 \mathrm{~Hz}$; after $20 \mathrm{~min}, 0.20 \pm 0.04 \mathrm{~Hz} ; p>0.05$; $n=35$ ). If the initial frequency was higher than $0.25 \mathrm{~Hz}$, we found that $5 \mu \mathrm{M}$ riluzole caused an initial slight decrease in frequency (control, $0.27 \pm 0.05 \mathrm{~Hz}$; after $20 \mathrm{~min}, 0.20 \pm 0.04 \mathrm{~Hz} ; p<0.05$; $n=15$ ), which then remained stable, whereas the intensity of ventral root bursts became progressively weaker (data not shown); thus, the burst frequency did not decrease in parallel with the burst amplitude. Similarly, the normal left-right and flexor-extensor coordination was retained as the bursts became weaker (Fig. 3B). It was difficult to wash out the effects of riluzole; typically, an acceptable washout took $>2 \mathrm{~h}$ (Fig. $3 A$ ). The slow kinetics of the actions of riluzole and reversal may reflect a slow penetration of this drug into the spinal cord When we used different concentrations of riluzole, we found that the apparent threshold for blockade of the locomotor rhythm was $\sim 2 \mu \mathrm{M}$ (which blocks $43 \%$ of $I_{\mathrm{Na}(\mathrm{P})}$; three of five preparations ceased to oscillate); at higher concentrations all of the preparations ceased to generate a rhythmic locomotor-like pattern in $<30 \mathrm{~min}$, and this elimination of the pattern was more rapid with higher riluzole concentrations.

We also investigated the effects of riluzole on cauda equinaevoked fictive locomotion in the neonatal mouse spinal cord (P1-P3) (Whelan et al., 2000; Gordon and Whelan, 2006). Fictive locomotion was monitored as usual on the IL2, rL2, and IL5 ventral roots. As seen in Figure 3D, stimulating the cauda equina reliably induced locomotor-like activities in the spinal cord, characterized by left-right and flexor-extensor alternation. DMSO $(0.05 \%)$ did not change the fictive locomotion evoked by stimulation of the cauda equina. Riluzole $(5 \mu \mathrm{M})$ was bath applied, and, $30 \mathrm{~min}$ later, the cauda equina-evoked fictive locomotion was totally abolished (Fig. $3 C)(n=5)$. The frequency of the cauda equina-evoked fictive locomotion was higher $(0.69 \pm 0.09$ $\mathrm{Hz} ; n=5)$ than that induced by bath application of NMDA, 5 -HT, and DA $(0.22 \pm 0.05 \mathrm{~Hz} ; n=64 ; p<0.01)$. As with chemically induced fictive locomotion, riluzole did not change the locomotor cycle frequency significantly (control, $0.69 \pm 0.09$ $\mathrm{Hz}$; after $20 \mathrm{~min}$ in riluzole, $0.65 \pm 0.08 \mathrm{~Hz} ; n=5 ; p>0.1$ ) but gradually decreased the locomotor burst amplitude until the motor pattern was no longer detectable. The effect of riluzole reversed after $2 \mathrm{~h}$.

These results suggest that riluzole may not have a major effect on the rhythm-generating components of the locomotor CPG but weakens the neuronal output to the MNs to the point at 


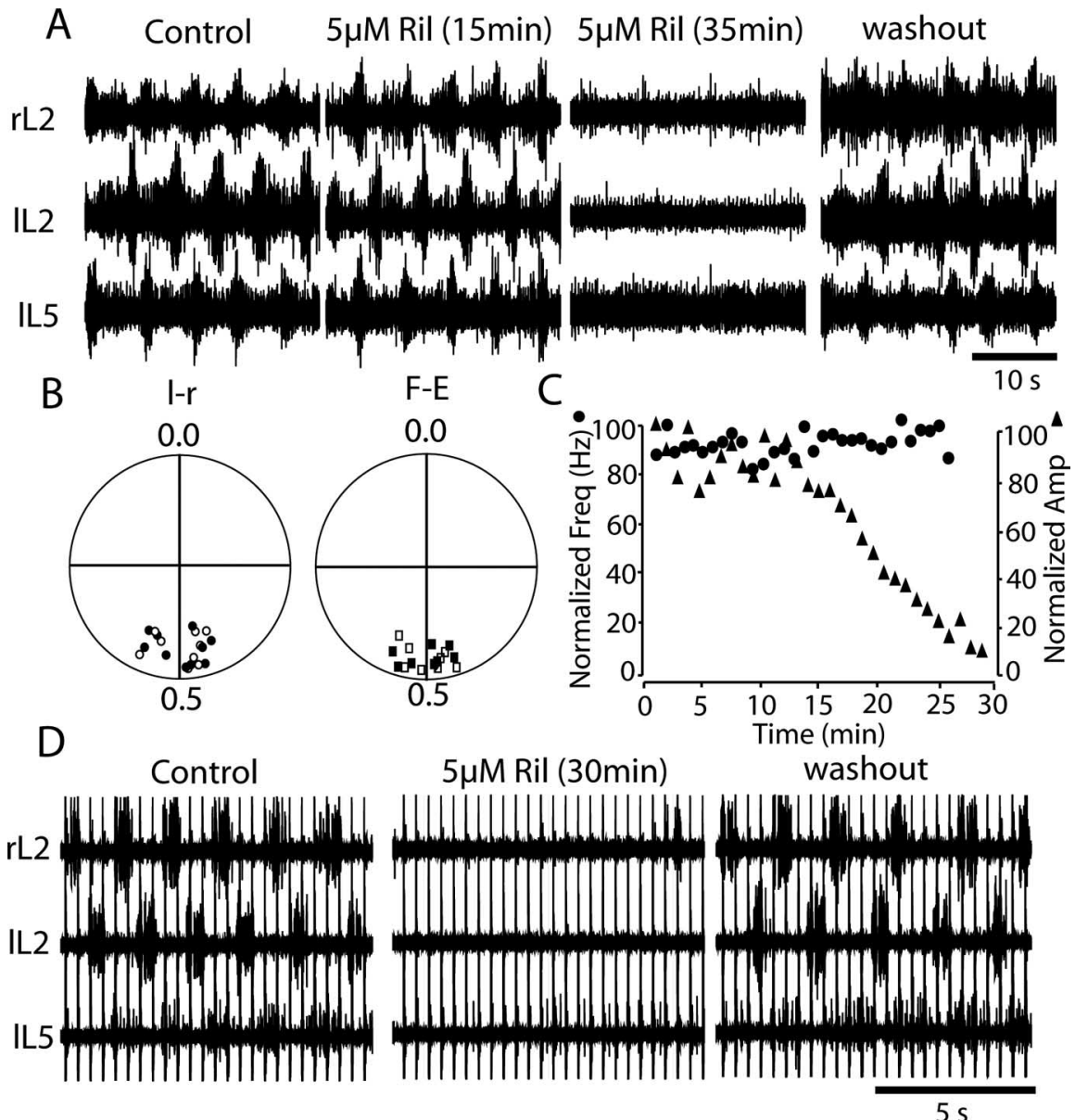

Figure 3. Riluzole reversibly inhibits fictive locomotion induced by application of chemicals or stimulation of the cauda equina. A, Locomotor-like activity was recorded from IL2, rL2, and IL5 after application of $6 \mu \mathrm{MNMDA}, 12 \mu \mathrm{m} 5-\mathrm{HT}$, and $18 \mu \mathrm{m} \mathrm{DA}$ in a P2 isolated spinal cord; fictive locomotion was reversibly weakened and eventually inhibited by $5 \mu$ m riluzole (Ril). $\boldsymbol{B}$, Riluzole did not affect the left-right (I-r) and flexor- extensor (F-E) alternation until the ventral root bursts became undetectable. $\boldsymbol{C}$, The time course of effects of riluzole on the burst frequency (filled circles) and amplitude (filled triangles). D, Locomotor-like activities were recorded from IL2, rL2, and IL5 by stimulating cauda equina in a P1 isolated mouse spinal cord; the evoked fictive locomotion was reversibly inhibited by $5 \mu$ m riluzole.

which fictive locomotion ceases. This could be attributable to blockade of $I_{\mathrm{Na}(\mathrm{P})}$, but riluzole also affects spike generation (Urbani and Belluzzi, 2000; Darbon et al., 2004; Kuo et al., 2005, 2006; Miles et al., 2005; Wu et al., 2005; Harvey et al., 2006), and this could also play a role. To further study this effect, we monitored the effects of riluzole on the properties of, and synaptic inputs to, MNs during fictive locomotion.

\section{Riluzole disrupts the firing pattern of motoneurons during} fictive locomotion

We recorded the activity from $15 \mathrm{~L} 2 \mathrm{MNs}$ during fictive locomotion from P0-P3 animals. Figure $4 A$ is one example of the firing pattern from an MN during fictive locomotion in a P1 preparation. As expected, these MNs fired rhythmically and in-phase with iL2 (Fig. 1 Diii). In three control experiments, 0.05\% DMSO had no effects on the firing pattern of MNs during fictive locomotion. In parallel with its effects on the extracellular ventral root recordings, $5 \mu \mathrm{M}$ riluzole progressively decreased the amplitude of MN membrane oscillations during fictive locomotion, until all rhythmic activity disappeared (Fig. $4 B$ ). The $\mathrm{MN}$ still received many EPSPs, but these did not arrive in rhythmic bursts, suggesting that riluzole might not have significant effects on normal synaptic transmission (see below). The average membrane oscillation amplitude decreased from $11.2 \pm 4.3$ to $7.8 \pm 2.9 \mathrm{mV}$ (riluzole, $15 \mathrm{~min}$ ) to $1.7 \pm 1.2 \mathrm{mV}$ (riluzole, $30 \mathrm{~min})(p<0.01$, one-way ANOVA; $n=12$ ) before becoming undetectable. Rhythmic action potential generation from the MNs was totally inhibited after $30 \mathrm{~min}$ in $5 \mu \mathrm{M}$ riluzole. Using voltage clamp, the synaptic currents in MNs at $-60 \mathrm{mV}$ during fictive locomotion were also monitored in eight experiments. All of these MNs received rhythmic bursts of EPSCs in-phase with iL2 root activity (Fig. $4 C)$. These rhythmic inward currents were also blocked after $30 \mathrm{~min}$ in $5 \mu \mathrm{M}$ riluzole (Fig. 4D). The MNs still received many synaptic currents, but they were not organized into a bursting pattern. This could be attributable to a decrease in rhythmic locomotor synaptic drive from the locomotor CPG. However, it is also possible that riluzole regulates the intrinsic membrane properties of MNs or their synapses and thus changes their firing pattern during fictive locomotion. Thus, we performed experiments on the effects of riluzole on the intrinsic membrane properties of MNs.

\section{Riluzole changes the intrinsic} membrane properties of MNs To monitor the direct effects of riluzole on MN firing properties, fast synaptic transmission was primarily blocked with antagonists to glutamate (50 $\mu \mathrm{M}$ AP-5 and 15 $\mu \mathrm{M}$ CNQX), glycine (10 $\mu \mathrm{M}$ strychnine), and GABA (10 $\mu \mathrm{M}$ picrotoxin) receptors in the isolated spinal cord. The average resting $\mathrm{MN}$ membrane potential was $-56 \pm 5 \mathrm{mV}(n=10)$. To standardize our measurements of the intrinsic membrane properties, the membrane potential was always held at $-60 \mathrm{mV}$ with a bias current. A series of $1 \mathrm{~s}$ positive current steps of increasing amplitude were applied, and, under control conditions, all of the MNs showed sustained repetitive firing $(n=10)$ (Fig. 5A). As reported previously by Kuo et al. (2006), application of $5 \mu \mathrm{M}$ riluzole for $15 \mathrm{~min}$ abolished the repetitive firing properties of the MNs, such that the MN fired only a single spike to a current step regardless of its amplitude $(n=10)$ (Fig. $5 B)$. We first speculated that riluzole might cause fast sodium channel inactivation, reducing the availability of transient sodium channels. To test this, short depolarizing current steps were applied and the MN responses were recorded. In the presence of $5 \mu \mathrm{M}$ riluzole, we found that MNs still reliably fired action potentials (Fig. $5 D, F$ ). In response to single pulses, the evoked action potential amplitude, measured from the holding membrane potential $(-60 \mathrm{mV})$ to the peak amplitude, was reduced by $5 \%$ by riluzole, from $78.4 \pm 6.5$ to $74.5 \pm 5.3 \mathrm{mV}$ (Fig. $5 C)(p<0.05 ; n=10)$. Riluzole also slightly depolarized the action potential threshold from $-45.3 \pm 4.2$ to $-41.6 \pm 5.7 \mathrm{mV}$ (Fig. $5 C)(p<0.05 ; n=10)$. However, riluzole had no significant effect on the absolute afterhyperpolarization potential (AHP) amplitude, measured as the minimal potential after each spike. 
Furthermore, when trains of short pulses were delivered, the MNs treated with riluzole could follow with spikes up to $50 \mathrm{~Hz}$ (Fig. $5 E, F$ ). When the MN was driven at $50 \mathrm{~Hz}$, the spike amplitude fell with each pulse: on average, the peak amplitude was decreased from $75.4 \pm 5.2 \mathrm{mV}$ for the first spike to $63.3 \pm 4.1 \mathrm{mV}$ for the fifth spike $(n=5 ; p<0.01)$. A similar reduction in spike amplitude was found in control experiments (first spike, $77.5 \pm 6.4 \mathrm{mV}$; fifth spike, $66.4 \pm 5.6 \mathrm{mV}$ ), and the difference in percentage reduction in spike amplitude with or without riluzole was not statistically significant $(p>0.05$ for fifth spike amplitude). These results show that riluzole does affect the firing properties of the MNs: it minimally reduces the spike amplitude and depolarizes the spike threshold and turns the response to a sustained depolarizing step from repetitive to single spiking.

Riluzole has no significant effect on synaptic transmission to $\mathrm{MNs}$ Because riluzole modestly decreased the peak action potential amplitude, we were concerned that it might affect spikeevoked synaptic transmission to MNs. To test this, EPSPs were evoked by stimulating the iL2 dorsal root and recording the reflex potential. The membrane potential was held at $-60 \mathrm{mV}$ by bias current to maintain a constant driving force on the EPSPs. The stimulation amplitude was adjusted to evoke $\sim 8 \mathrm{mV}$ EPSPs from the MN. A typical recording is shown in Figure $6 \mathrm{~A}$. Bath application of $5 \mu \mathrm{M}$ riluzole for 30 min only slightly decreased the amplitude of the EPSP (Fig. 6B). Application of the glutamate antagonists, $50 \mu \mathrm{M}$ AP-5 and $15 \mu \mathrm{M} C N Q X$, totally blocked the EPSP (Fig. 6C), demonstrating that it was a glutamatergic synapse. In three additional experiments, we evoked EPSPs in MNs by stimulating the ipsilateral rostral hemicord. These EPSPs were also glutamatergic, and $5 \mu \mathrm{M}$ riluzole also had little effect on the EPSP amplitude. For statistical analysis, we pooled all of the EPSP data and found that $5 \mu \mathrm{M}$ riluzole has no significant effect on the EPSP amplitude (control, $8.3 \pm 1.1 \mathrm{mV}$; riluzole, $7.4 \pm 2.1 \mathrm{mV} ; n=6 ; p>0.05)$.

Because riluzole also slightly depolarizes the action potential threshold, we investigated whether this affects synaptically driven action potential generation in MNs. The MN membrane potential was depolarized to $-50 \mathrm{mV}$, close to action potential threshold; a weak stimulation from the iL2 dorsal root or rostral hemicord reliably evoked a synaptically driven action potential (Fig. $6 D)$. Riluzole at $5 \mu \mathrm{M}$ caused these MNs to change from repetitive firing to single spiking in response to a sustained depolarizing step (Fig. $6 E$ ), but the synaptically driven action potential was unaffected (Fig. $6 E)(n=4)$. After washout of riluzole, blockade of glutamatergic transmission with $50 \mu \mathrm{M}$ AP-5 and $15 \mu \mathrm{M}$ CNQX eliminated the synaptically driven EPSP but not the re- petitive firing pattern to current injections (Fig. $6 D, F$ ). Thus, our data suggest that, at $5 \mu \mathrm{M}$, riluzole has little effect on spike-evoked synaptic transmission to MNs.

Riluzole disrupts the firing pattern of CINs during fictive locomotion

CINs are involved in the regulation of left-right coordination (Butt et al., 2002; Butt and Kiehn, 2003; Zhong et al., 2006a,b); they might also participate in setting the frequency of fictive locomotion because lesion studies show that the cycle frequency is slower when the ventral commissure is lesioned (Kjaerulff and Kiehn, 1996) or the spinal cord is hemisected (Hinckley et al., 2005). We decided to look for effects of riluzole on neuronal activity within the locomotor pattern-generating network and focused on the CINs. We recorded from 18 CINs, including nine ascending CINs (aCINs), seven descending CINs (dCINs), and two bifurcating CINs (adCINs). As we reported previously (Zhong et al., 2006b), neither of the two adCINs fired rhythmi- 

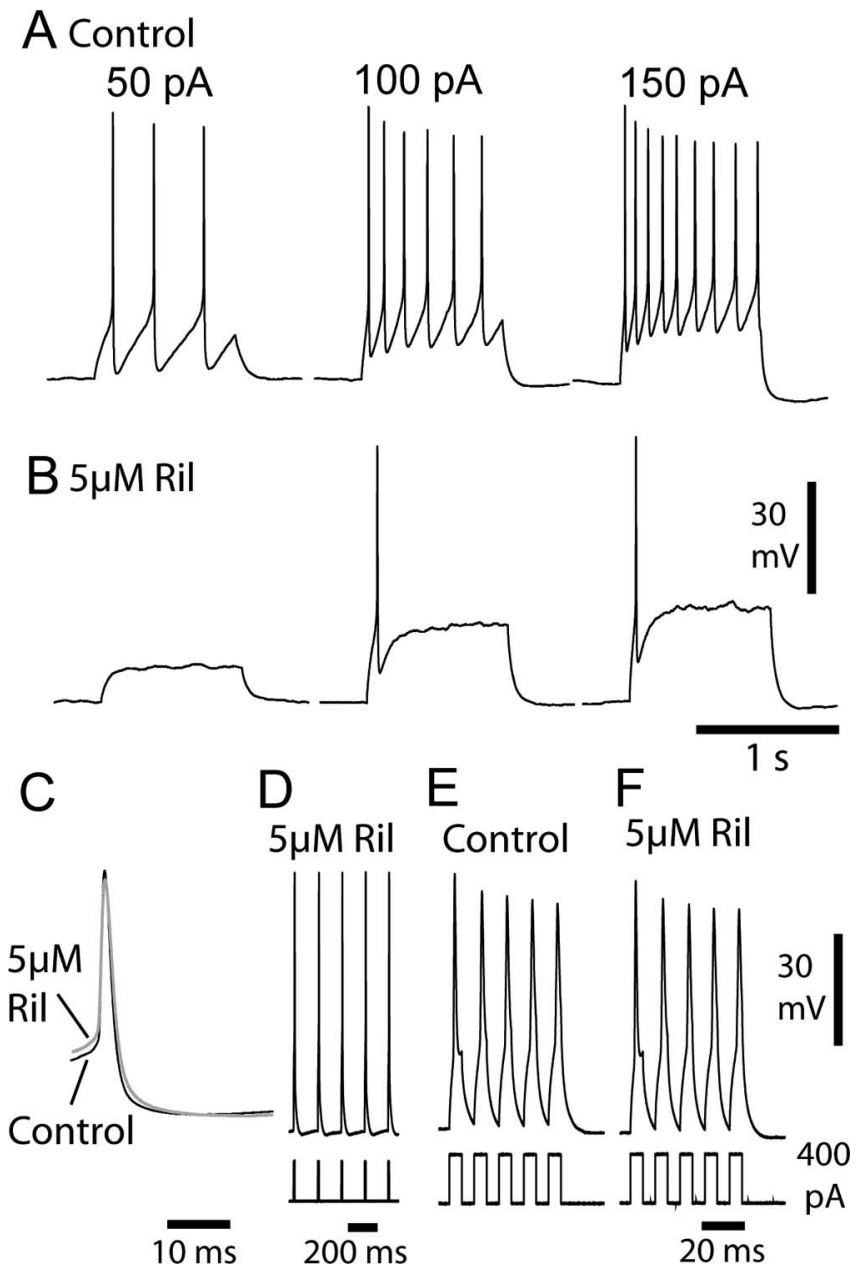

Figure 5. Role of $/_{\mathrm{Na}(\mathrm{P})}$ in controlling the intrinsic membrane properties of partially synaptically isolated $\mathrm{MNs}$. $A$, Tonic responses of an $\mathrm{MN}$ to a series of current injections in the presence of $50 \mu \mathrm{M}$ AP-5, $15 \mu \mathrm{M}$ CNQX, $10 \mu \mathrm{m}$ strychnine, and $10 \mu \mathrm{m}$ picrotoxin in a P3 spinal cord. B, Phasic responses of the $\mathrm{MN}$ to a series of current injections during application of $5 \mu \mathrm{m}$ riluzole (Ril). $C$, Comparison of the action potentials elicited by $5 \mathrm{~Hz}$ transient inputs during control and riluzole application. $\boldsymbol{D}$, Action potentials triggered by $5 \mathrm{~Hz}$ transient inputs during riluzole application. $\boldsymbol{E}$, $\boldsymbol{F}$, Action potentials triggered by $50 \mathrm{~Hz}$ transient inputs during control and riluzole application, respectively.

cally during fictive locomotion, so we did not include them in our analysis. Eleven of the remaining 16 CINs fired rhythmically, with widely varying phases of peak activity, during fictive locomotion. In control experiments, DMSO $(0.05 \%)$ had no effect on the firing pattern of one dCIN and two aCINs during fictive locomotion (data not shown). After regular bursting was initiated, $5 \mu \mathrm{M}$ riluzole was added. As with the MNs, we found that, over time, riluzole reduced and eventually eliminated both the rhythmic firing and the amplitude of the membrane potential oscillation of both aCINs and dCINs (Fig. 7B). For statistical analysis, we pooled the data from aCINs and dCINs. During riluzole application, the subthreshold membrane potential oscillation amplitude was progressively decreased (control, $7.5 \pm 3.2 \mathrm{mV}$; riluzole after $15 \mathrm{~min}, 5.1 \pm 2.4 \mathrm{mV}$; riluzole after $30 \mathrm{~min}, 1.3 \pm 1.2 \mathrm{mV} ; p<$ 0.01 , one-way ANOVA; $n=8$ ) before becoming undetectable. This decrease could result from a decrease of locomotor-related synaptic drive or from a direct effect of riluzole on the intrinsic membrane properties of CINs. The synaptic currents during fictive locomotion were also monitored in six experiments by voltage-clamp recordings at a holding potential of $-60 \mathrm{mV}$. Four of the six CINs received rhythmic outward synaptic currents in varying phases with L2 root activity (Fig. 7C). This locomotorrelated inhibitory synaptic current was blocked by $5 \mu \mathrm{M}$ riluzole after $30 \mathrm{~min}$ (Fig. 7D). As we saw with the MNs, there were still many synaptic currents in the CINs under these conditions, but they were not rhythmically organized. Thus, our data suggest that the strength of the rhythmic locomotor synaptic drive to CINs was reduced and eventually abolished by riluzole.

\section{Riluzole changes the intrinsic membrane properties of CINs} In addition to reducing rhythmic synaptic drive to CINs, riluzole could also affect their intrinsic properties, and this could contribute to their reduced activity. CINs were recorded in slice preparations and isolated from most fast synaptic transmissions with $50 \mu \mathrm{M}$ AP-5, $15 \mu \mathrm{M}$ CNQX, $10 \mu \mathrm{M}$ strychnine, and $10 \mu \mathrm{M}$ picrotoxin. Only aCINs or dCINs were selected for this study. In response to sustained depolarizing current steps, 17 CINs (including nine dCINs and eight aCINs) displayed sustained repetitive firing with the spike frequency increasing with current step amplitude (Fig. $8 \mathrm{~A})$. As a control, DMSO $(0.05 \%)$ alone had no effects on the firing properties of synaptically isolated CINs $(n=$ 5 ). As was found with the MNs, $5 \mu \mathrm{M}$ rilzuole changed the response of 12 CINs to prolonged current steps from sustained repetitive firing to single spiking, regardless of step amplitude (Fig. $8 \mathrm{~B}$ ). To test whether there were still transient sodium channels available to sustain spikes during the prolonged pulse, four very brief ( $5 \mathrm{~ms}$ ) depolarizing steps were superimposed on the prolonged pulse. The CINs were able to respond to these transient inputs reliably with additional action potentials during the depolarizing step (Fig. 8C), indicating the continued availability of transient sodium channels. The effects of riluzole were slowly reversible after $\sim 2 \mathrm{~h}(n=4)$.

We found that riluzole moderately reduces the amplitude and spike threshold of single action potentials, as it did with MNs (action potential threshold: control, $-37.2 \pm 3.6 \mathrm{mV}$; riluzole, $-34.6 \pm 3.9 \mathrm{mV} ; p<0.05, n=12$; action potential amplitude: control, $68.4 \pm 4.2 \mathrm{mV}$; rilzuole, $64.8 \pm 4.5 \mathrm{mV} ; p<0.01, n=$ $12)$. Thus, we tested whether riluzole affected spike-evoked synaptic transmission to CINs.

\section{Riluzole does not affect spike-evoked synaptic transmission to dCINs}

We found that stimulation of the rostral contralateral hemicord often evoked excitatory synaptic potentials in dCINs, which allowed us to investigate whether riluzole has any effects on synaptic transmission to CINs. The membrane potential was held at $-60 \mathrm{mV}$ by bias current, and the hemicord stimulation intensity was adjusted to evoke $\sim 8 \mathrm{mV}$ EPSPs. Figure $9 A$ is one example of an EPSP evoked by rostral hemicord stimulation. Riluzole $(5 \mu \mathrm{M})$ did not significantly decrease the EPSP amplitude induced by rostral contralateral hemicord stimulation (control, $7.6 \pm 1.2$ $\mathrm{mV}$; riluzole, $7.1 \pm 1.6 \mathrm{mV} ; n=5 ; p>0.05$ ) (Fig. 9A, $B$ ). CNQX at $15 \mu \mathrm{M}$ totally eliminated the EPSP (and uncovered a simultaneous IPSP in the example of Fig. 9C), indicating that the EPSPs were mediated by AMPAergic glutamate receptors. In a number of control experiments, rostral or caudal hemicord stimulation induced EPSPs $(n=10)$ or IPSPs $(n=6)$ in interneurons that turned out not to be CINs. In all of these cases, $5 \mu \mathrm{M}$ riluzole also did not reduce the EPSP or IPSP amplitude (data not shown), indicating that $5 \mu \mathrm{M}$ riluzole does not affect spike-evoked synaptic transmission in general. We also found that riluzole does not inhibit the propagation of the antidromic action potential evoked by caudal hemicord stimulation in dCINs (Fig. 9D,E). 


\section{Discussion}

This study provides insights into the role of $I_{\mathrm{Na}(\mathrm{P})}$ in the control of intrinsic membrane properties of CINs and MNs and in the function of the locomotor patterngenerating network in the neonatal mouse spinal cord. We found that $I_{\mathrm{Na}(\mathrm{P})}$ is essential for the generation of fictive locomotion; however, the role of $I_{\mathrm{Na}(\mathrm{P})}$ is not straightforward.

\section{Riluzole block of $I_{\mathrm{Na}(\mathrm{P})}$ in spinal neurons}

CINs possess a slowly inactivating $I_{\mathrm{Na}(\mathrm{P})}$ that activates well below the threshold for action potential generation. As has been found in other preparations (Urbani and Belluzzi, 2000; Miles et al., 2005; Wu et al., 2005), riluzole blocks $I_{\mathrm{Na}(\mathrm{P})}$ with an $\mathrm{IC}_{50}$ of $2.8 \mu \mathrm{M}$; at $5 \mu \mathrm{M}$ riluzole, at which most of our experiments were performed, $I_{\mathrm{Na}(\mathrm{P})}$ is blocked by $\sim 67 \%$. Kuo et al. (2006) have shown recently similar properties and riluzole block of $I_{\mathrm{Na}(\mathrm{P})}$ in mouse spinal MNs. Thus, both MNs and CINs express a riluzole-sensitive $I_{\mathrm{Na}(\mathrm{P})}$.

A major issue of the use of riluzole is its specificity: other studies have shown that riluzole also blocks potassium channels (Zona et al., 1998; Duprat et al., 2000; Cao et al., 2002; Ahn et al., 2005), calcium channels (Huang et al., 1997), and glutamatergic synaptic transmission (Zona et al., 2002; Albo et al., 2004). However, it is unlikely that the effects of riluzole reported here are attributable to these nonspecific effects. First, they are only observed at higher concentrations (10-300 $\mu \mathrm{M}$ ) (Huang et al., 1997; Zona et al., 1998; Duprat et al., 2000; Cao et al., 2002; Ahn et al., 2005). Second, riluzole has no significant effects on the action potential halfwidth and AHP amplitude, which would be modified if riluzole blocked potassium or calcium channels. Third, the glutamatergic synapses onto CINs and MNs are not weakened by riluzole. Another factor is whether the actions of riluzole are mediated by blockade of the transient sodium current $\left(I_{\mathrm{Na}(\mathrm{T})}\right)$, which mediates the spike. Our data suggest that riluzole does reduce this current, because the peak amplitude of action potentials was reduced by 5\% in both CINs and MNs (Kuo et al., 2006). Because the amplitude of the spike is related in a highly nonlinear manner to $I_{\mathrm{Na} \text { (T) }}$ (Swensen and Bean, 2003), this could represent a significant reduction in $I_{\mathrm{Na}(\mathrm{T})}$. However, both CINs and MNs could still follow a train of depolarizing pulses at up to $50 \mathrm{~Hz}$, the attenuation in spike amplitude during a high-frequency train was not affected by $5 \mu \mathrm{M}$ riluzole, and spike-evoked transmission was also not affected. Thus, although it is likely that $5 \mu \mathrm{M}$ riluzole does reduce $I_{\mathrm{Na} \text { (T) }}$, this does not greatly affect the function of the action potentials. We conclude that the effects we observed with $5 \mu \mathrm{M}$ riluzole primarily reflect its selective blockade of $I_{\mathrm{Na}(\mathrm{P})}$.

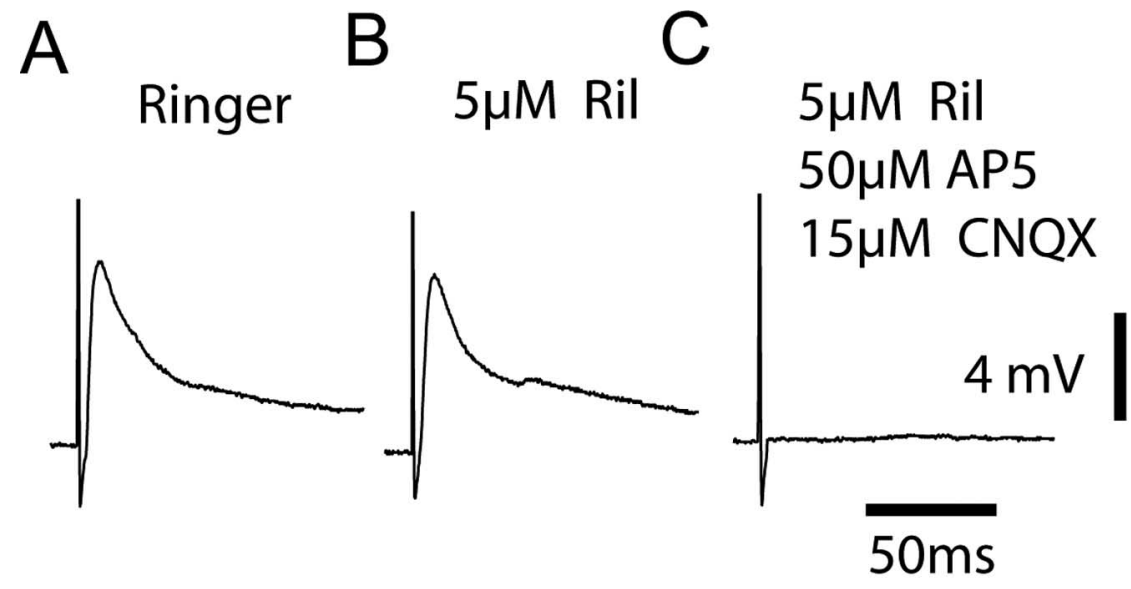

D Ringer E $5 \mu \mathrm{M}$ Ril F $50 \mu \mathrm{M}$ AP5 $15 \mu \mathrm{M}$ CNQX
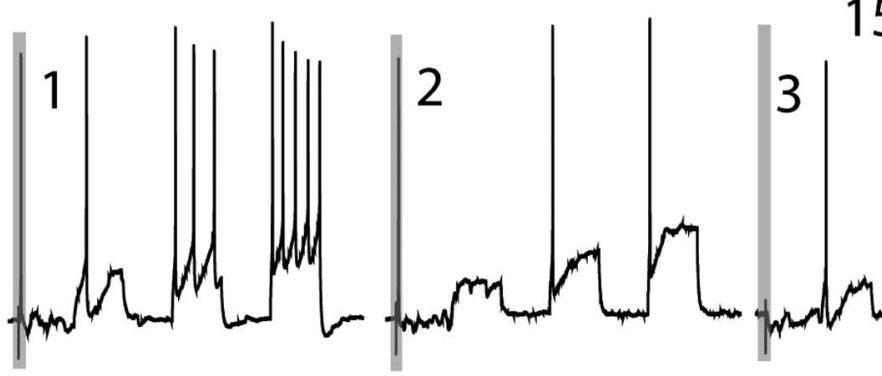

3

$40 \mathrm{mV}$

Figure 6. Effect of $I_{\mathrm{Na}(\mathrm{P})}$ on synaptic inputs to MNs.A, A reflex EPSP in a P3 spinal cord evoked by stimulating the dorsal iL2 root. $\boldsymbol{B}$, Riluzole $(5 \mu \mathrm{m})$ (Ril) has no effect on the reflex EPSP. C, AP-5 at $50 \mu \mathrm{m}$ and $15 \mu \mathrm{m}$ CNQX block the reflex EPSP. D, A synaptically driven action potential in an MN shown in the gray square and amplified below, evoked by stimulating the dorsal iL2 root in a P2 cord. Subsequent square pulse current injections evoke tonic spiking in the MN. $\boldsymbol{E}$, Riluzole (5 $\mu \mathrm{m})$ has no effect on the synaptically driven action potential from the same MN as $\boldsymbol{D}$ (gray square, amplified below), although it eliminates tonic spiking in response to tonic current injection. $\boldsymbol{F}$, After washout of riluzole, tonic spiking responses to current injection are restored, and $50 \mu \mathrm{M}$ AP-5 and $15 \mu \mathrm{M}$ CNQX eliminate the synaptically driven action potential in the same MN.

\section{Riluzole blocks fictive locomotion in the neonatal mouse spinal cord}

Our most striking result was that low concentrations $(2-5 \mu \mathrm{M})$ of riluzole could eliminate fictive locomotion, evoked by either bath application of NMDA, 5-HT, and DA or by cauda equina stimulation. The primary effect of riluzole was to progressively reduce the amplitude of the ventral root burst discharge, with little effect on the cycle frequency or left-right and flexor-extensor alternation until just before the motor pattern failed altogether (Fig. $3 B, C)$. When the cycle frequency of fictive locomotion evoked by NMDA, 5-HT, and DA was slow ( $0.2 \mathrm{~Hz}$ and below), there was no effect on the cycle frequency at all; at higher cycle frequencies, there was a small $(25 \%)$ initial reduction in cycle frequency. However, riluzole did not decrease the cycle frequency $(0.69 \pm$ 0.09 ) of fictive locomotion evoked by stimulation of the cauda 


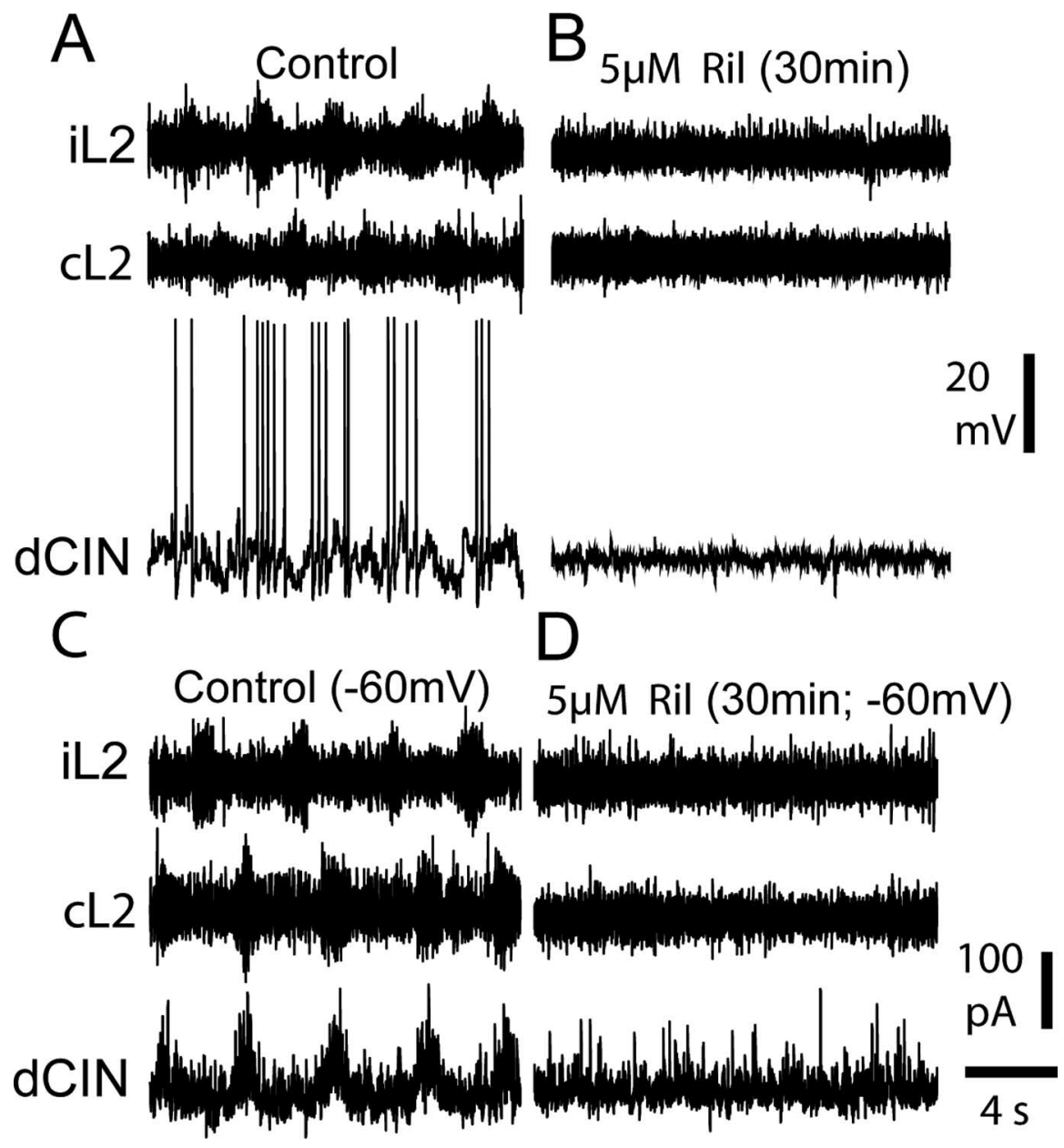

Figure 7. Effects of riluzole on the rhythmic activity of CINs during fictive locomotion induced by application of NMDA, 5-HT, and DA. $\boldsymbol{A}$, Intracellular recordings from a dCIN in a P3 isolated spinal cord in current clamp and the iL2 and contralateral L2 (CL2) ventral root bursts. $\boldsymbol{B}$, Riluzole (Ril) blocks the rhythmic activity of the dCIN in parallel with the blockade of fictive locomotion measured from the ventral roots. $\boldsymbol{C}$, Voltage-clamp recordings from the same $\mathrm{dCIN}$, showing rhythmic IPSCs in-phase with the contralateral L2 ventral root bursts. D, Riluzole abolishes the IPSCs in the dCIN in parallel with its reduction in fictive locomotion. pability; (2) reduction in spike-evoked synaptic transmission; and (3) reduction in the amount of rhythmic synaptic input from the CPG. We studied the effect of riluzole on the intrinsic firing properties of MNs after pharmacological blockade of most fast synaptic inputs. As has been found previously in mouse MNs (Kuo et al., 2005, 2006; Miles et al., 2005; Harvey et al., 2006), cortical neurons (Urbani and Belluzzi, 2000), and other spinal neurons (Darbon et al., 2004), riluzole changed $\mathrm{MN}$ responses to depolarizing current steps from tonic firing to single spikes, regardless of step amplitude. Kuo et al. (2006) showed that $I_{\mathrm{Na}(\mathrm{P})}$ helps the MN to depolarize to threshold before the inactivation of $I_{\mathrm{Na} \text { (T) }}$, and, if it is blocked, the fast sodium channels inactivate before the threshold for the next spike is reached. However, MNs can still fire repetitively at up to $50 \mathrm{~Hz}$ in riluzole if driven by brief pulses (Fig. $5 F$ ), and the decay in spike amplitude during these high-frequency trains is not affected by riluzole. These results suggest that $I_{\mathrm{Na}(\mathrm{P})}$ plays an important role to determine the response of MNs to sustained inputs.

Riluzole does have two effects on single spikes in MNs: it slightly depolarizes the threshold for spike initiation from -45 to $-42 \mathrm{mV}$, and it reduces the spike amplitude by $5 \%$. These effects could reduce the MN output to muscles by making the neurons slightly less excitable and possibly by reducing transmitter release during the smaller action potential. As described below, we believe that the small reduction in spike amplitude does not affect transmitter release, but the increase in spike threshold may be important in weakening equina before cessation of the motor rhythm. These results suggest that, although riluzole may have a modest effect on the rhythm-generating elements of the locomotor CPG (LafreniereRoula and McCrea, 2005; Rybak et al., 2006), its main effects are on the pattern-generating component, to weaken the output to the motoneurons. It is not clear why the rhythm-generating elements are not more affected by riluzole; they could lack significant $I_{\mathrm{Na}(\mathrm{P})}$ or may not fire multiple action potentials per cycle. Additional understanding of this question will require identification of the neurons that participate in rhythm generation.

Effect of riluzole on MNs and CINs during fictive locomotion During fictive locomotion, both CINs and MNs fire rhythmically, with synaptically driven oscillations. In voltage clamp, we found that CINs and MNs receive strong rhythmic bursts of synaptic currents in-phase with the motor pattern. In riluzole, the slow oscillations and rhythmic synaptic currents in MNs and CINs became progressively smaller with time until they disappeared; this apparent reduction in synaptic drive paralleled the reduction in ventral root burst amplitude.

This reduction in rhythmic MN and CIN activity could arise from three possible sources: (1) reduction in intrinsic firing ca- the MN rhythmic spike frequency during riluzole. Second, riluzole could affect the efficacy of synaptic transmission to MNs, via presynaptic or postsynaptic mechanisms. However, riluzole had no significant effect on reflex EPSPs evoked by dorsal root stimulation. It is possible that EPSPs from other interneurons might be more strongly affected by riluzole, but measurements from other interneurons (see below) also show no effects on synaptic transmission. Thus, the most likely explanation for the reduction in MN slow oscillation and spiking during riluzole is our third mechanism, a reduction in the amount of synaptic drive from the locomotor CPG, although the elevation in spike threshold and the inability to fire tonically during a persistent depolarization could contribute as well.

Similar results were obtained when we studied the effects of riluzole on CINs. Riluzole abolishes the ability of the CINs to fire tonically during a maintained current step but retained their ability to respond to brief pulses, even during a prolonged depolarizing current step (Fig. 8). Riluzole also reduced the amplitude of single action potentials and slightly depolarized the threshold for spike initiation. Finally, riluzole did not affect the amplitude of EPSPs evoked by contralateral hemicord stimulation. Following the same arguments made above for MNs, we conclude that CINs 
A Control $10 \mathrm{pA}$ $20 \mathrm{pA}$ $30 \mathrm{pA}$
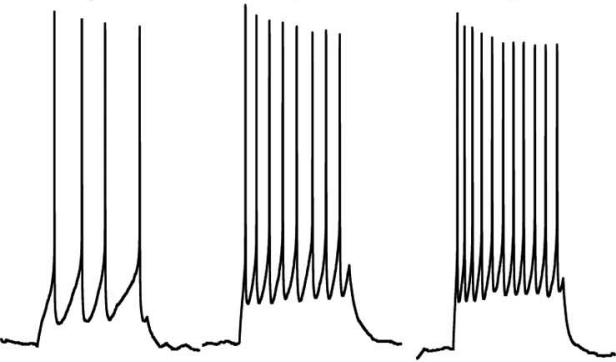

B $5 \mu \mathrm{M}$ Ril

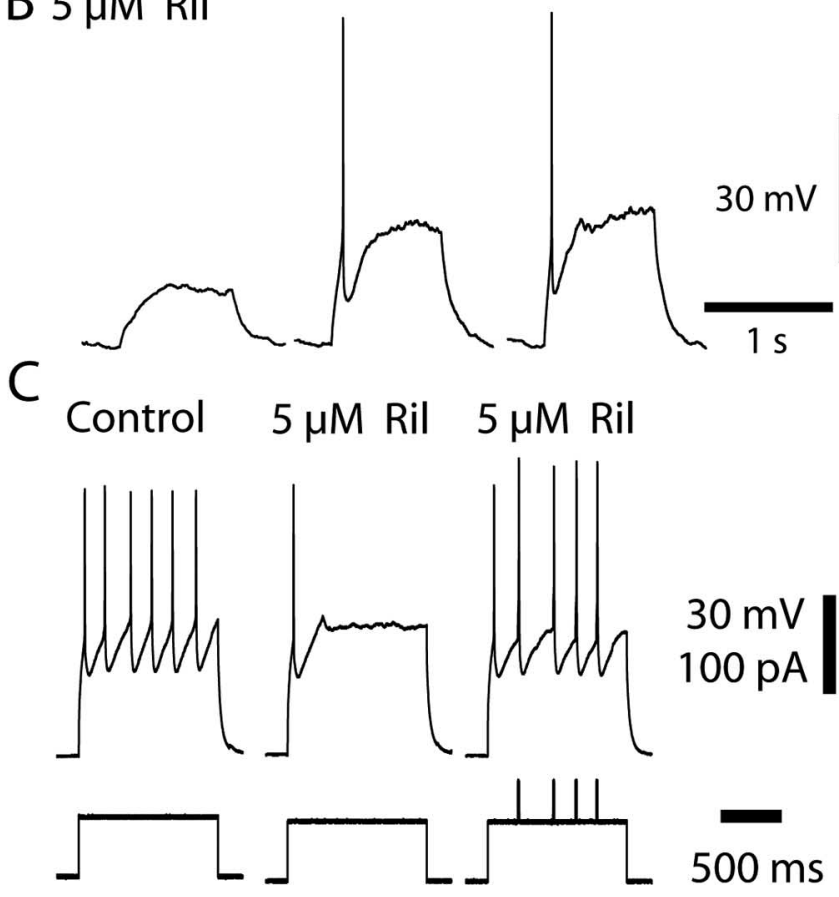

Figure 8. Role of $I_{\mathrm{Na}(\mathrm{P})}$ in the intrinsic membrane properties of CINs in spinal cord slice preparations. $\boldsymbol{A}$, Tonic responses to a series of current injections of a dCIN that is partially isolated from synaptic inputs by application of $50 \mu \mathrm{m}$ AP-5, $15 \mu \mathrm{M}$ CNQX, $10 \mu \mathrm{m}$ strychnine, and $10 \mu \mathrm{m}$ picrotoxin in a P2 slice. $\boldsymbol{B}$, Riluzole abolishes the tonic responses of the $\mathrm{dCIN}$ to a series of current injections. C, Tonic potentials elicited by a square pulse current injection (left) are eliminated by riluzole (middle), but brief transient current pulses can still evoke spikes during the current step in the presence of riluzole.

reduce their firing frequency during riluzole primarily attributable to a reduction in the synaptic drive from other interneurons in the CPG; these are unfortunately not yet known, so direct studies of their activity will have to await their identification. Because hemisection of the spinal cord slows fictive locomotion (Kjaerulff and Kiehn, 1996; Hinckley et al., 2005), the reduction in CIN activity could contribute to the very modest reduction in cycle frequency during riluzole in preparations cycling faster than $0.25 \mathrm{~Hz}$.

\section{A hypothesis for the role of $I_{\mathrm{Na}(\mathrm{P})}$ in the generation of fictive locomotion}

Our results show that $I_{\mathrm{Na}(\mathrm{P})}$ plays a subtle yet essential role in the generation of the locomotor pattern in the mouse spinal cord. We found similar effects of riluzole on CINs and MNs and suggest that these effects might be general among neurons in the locomotor CPG. Reduction of the persistent sodium

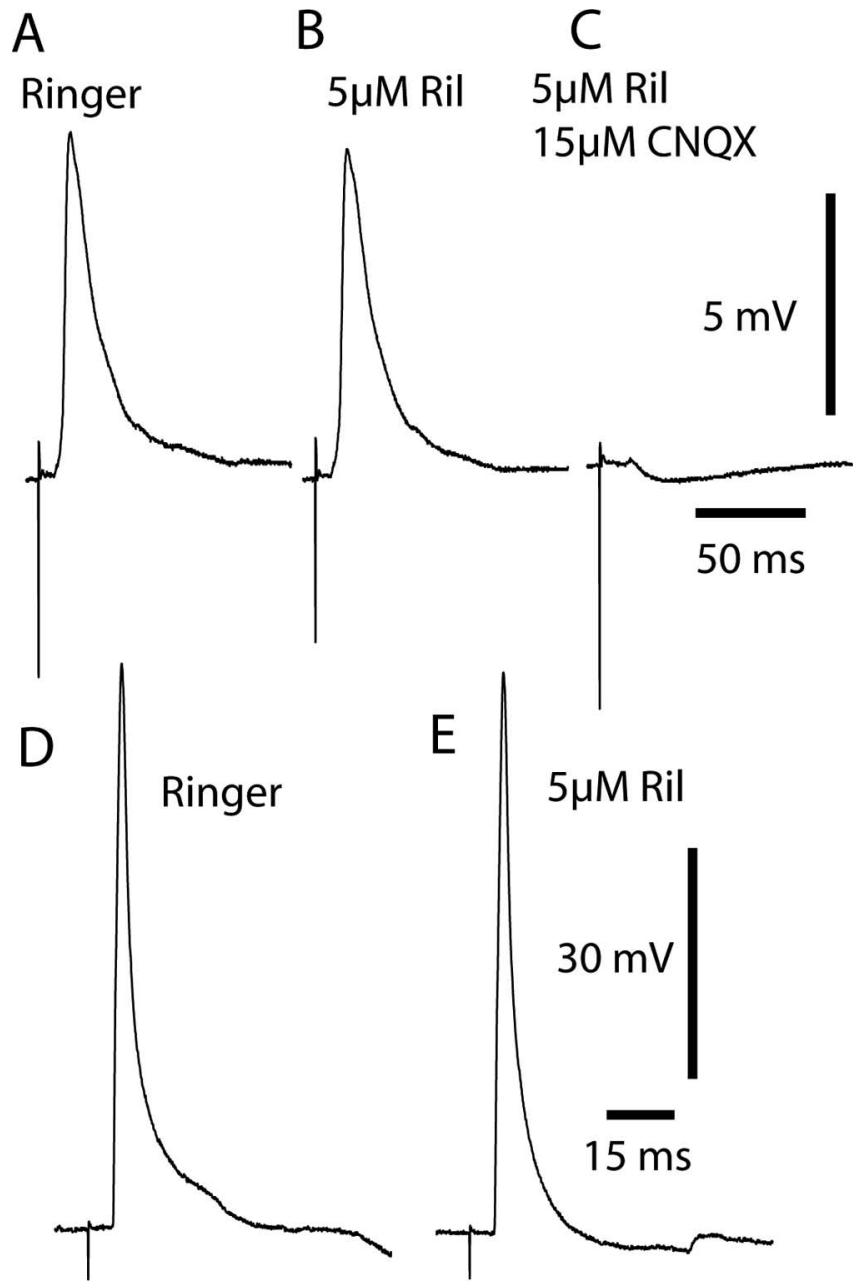

Figure 9. Riluzole does not block synaptic transmission to dCINs. A, An EPSP recorded from a dCIN from a P1 spinal cord, evoked by stimulating contralateral rostral hemicord. $B$, Riluzole (Ril) has no effect on the evoked EPSP. C, CNQX (15 $\mu \mathrm{M})$ abolishes the EPSP and uncovers a simultaneous IPSP. D, E, Antidromic action potentials triggered by caudal hemicord stimulation are not affected by riluzole application.

current has only modest effects on the timing mechanisms that control the cycle frequency; rather, the intensity of synaptic drive at each level within the locomotor CPG, including its output to the MNs, is progressively reduced until rhythmic firing becomes undetectable. Based on our studies of CINs and MNs, two intrinsic mechanisms could contribute to this reduction in activity. First, the spike threshold is slightly elevated, so the neurons require slightly more synaptic drive to fire an action potential. If this occurred throughout the locomotor network, a cumulative effect of weakened spiking of each neuron would result in a large reduction in final drive to the MNs. Second, in the presence of riluzole, both CINs and MNs are unable to spike tonically in response to sustained depolarization (Kuo et al., 2006). If there were neurons that underwent sustained depolarizations, perhaps by intrinsic mechanisms (Wilson et al., 2005), this effect could reduce the output from these neurons, thus reducing the output from any postsynaptic neurons and neurons downstream in the network. These hypotheses await additional verification as more neurons in the locomotor CPG are identified. 


\section{References}

Ahn HS, Choi JS, Choi BH, Kim MJ, Rhie DJ, Yoon SH, Jo YH, Kim MS, Sung KW, Hahn SJ (2005) Inhibition of the cloned delayed rectifier $\mathrm{K}^{+}$channels, Kv1.5 and Kv3.1, by riluzole. Neuroscience 133:1007-1019.

Albo F, Pieri M, Zona C (2004) Modulation of AMPA receptors in spinal motor neurons by the neuroprotective agent riluzole. J Neurosci Res 78:200-207.

Berkowitz A, Stein PSG (1994) Activity of descending propriospinal axons in the turtle hindlimb enlargement during two forms of fictive scratching: phase analyses. J Neurosci 14:5105-5119.

Buschges A, Wikstrom MA, Grillner S, El Manira A (2000) Roles of highvoltage-activated calcium channel subtypes in a vertebrate spinal locomotor network. J Neurophysiol 84:2758-2766.

Butt SJ, Kiehn O (2003) Functional identification of interneurons responsible for left-right coordination of hindlimbs in mammals. Neuron 38:953-963.

Butt SJ, Harris-Warrick RM, Kiehn O (2002) Firing properties of identified interneuron population in the mammalian hindlimb central pattern generator. J Neurosci 22:9961-9971.

Butt SJ, Lundfald L, Kiehn O (2005) EphA4 defines a class of excitatory locomotor-related interneurons. Proc Natl Acad Sci USA 102:14098-14103.

Cao YJ, Dreixler JC, Couey JJ, Houamed KM (2002) Modulation of recombinant and native neuronal SK channels by the neuroprotective drug riluzole. Eur J Pharmacol 449:47-54.

Carlin KP, Dai Y, Jordan LM (2006) Cholinergic and serotonergic excitation of ascending commissural neurons in the thoraco-lumbar spinal cord of the neonatal mouse. J Neurophysiol 95:1278-1284.

Cazalets JR, Squalli-Houssaini Y, Clarac F (1992) Activation of the central pattern generators for locomotion by serotonin and excitatory amino acids in neonatal rat. J Physiol (Lond) 455:187-204.

Cazalets JR, Borde M, Clarac F (1995) Localization and organization of the central pattern generator for hindlimb locomotion in newborn rats. J Neurosci 15:4943-4951.

Cowley KC, Schmidt BJ (1997) Regional distribution of the locomotor pattern-generating network in the neonatal rat spinal cord. J Neurophysiol 77:247-259.

Crill WE (1996) Persistent sodium current in mammalian central neurons. Annu Rev Physiol 58:349-362.

Darbon P, Yvon C, Legrand JC, Streit J (2004) INaP underlies intrinsic spiking and rhythm generation in networks of cultured rat spinal cord neurons. Eur J Neurosci 20:976-988.

Del Negro CA, Morgado-Valle C, Feldman JL (2002) Respiratory rhythm: an emergent network property? Neuron 34:821-830.

Del Negro CA, Morgado-Valle C, Hayes JA, Mackay DD, Pace RW, Crowder EA, Feldman JL (2005) Sodium and calcium current-mediated pacemaker neurons and respiratory rhythm generation. J Neurosci 25:446-453.

Duprat F, Lesage F, Patel AJ, Fink M, Romey G, Lazdunski M (2000) The neuroprotective agent riluzole activates the two $\mathrm{P}$ domain $\mathrm{K}(+)$ channels TREK-1 and TRAAK. Mol Pharmacol 57:906-912.

Eide AL, Glover J, Kjaerulff O, Kiehn O (1999) Characterization of commissural interneurons in the lumbar region of the neonatal rat spinal cord. J Comp Neurol 403:332-345.

El Manira A, Tegnér J, Grillner S (1994) Calcium-dependent potassium channels play a critical role for burst termination in the locomotor network in lamprey. J Neurophysiol 72:1852-1861.

Gordon IT, Whelan PJ (2006) Monoaminergic control of cauda-equinaevoked locomotion in the neonatal mouse spinal cord. J Neurophysiol 96:3122-3129.

Gosgnach S, Lanuza GM, Butt SJ, Saueressig H, Zhang Y, Velasquez T, Riethmacher D, Callaway EM, Kiehn O, Goulding M (2006) V1 spinal neurons regulate the speed of vertebrate locomotor outputs. Nature 440:215-219.

Harris-Warrick RM (2002) Voltage-sensitive ion channels in rhythmic motor systems. Curr Opin Neurobiol 12:646-651.

Harris-Warrick RM, Marder E (1991) Modulation of neural networks for behavior. Annu Rev Neurosci 14:39-57.

Harris-Warrick RM, Coniglio LM, Barazangi N, Guckenheimer J, Gueron S (1995) Dopamine modulation of transient potassium current evokes phase shifts in a central pattern generator network. J Neurosci $15: 342-358$
Harris-Warrick RM, Johnson BR, Peck JH, Kloppenburg P, Ayali A, Skarbinski J (1998) Distributed effects of dopamine modulation in the crustacean pyloric network. Ann NY Acad Sci 860:155-167.

Harvey PJ, Li Y, Li X, Bennett DJ (2006) Persistent sodium currents and repetitive firing in motoneurons of the sacrocaudal spinal cord of adult rats. J Neurophysiol 96:1141-1157.

Hess D, El Manira A (2001) Characterization of a high-voltage-activated IA current with a role in spike timing and locomotor pattern generation. Proc Natl Acad Sci USA 98:5276-5281.

Hinckley CA, Hartley R, Wu L, Todd A, Ziskind-Conhaim L (2005) Locomotor-like rhythms in a genetically distinct cluster of interneurons in the mammalian spinal cord. J Neurophysiol 93:1439-1449.

Huang CS, Song JH, Nagata K, Yeh JZ, Narahashi T (1997) Effects of the neuroprotective agent riluzole on the high voltage-activated calcium channels of rat dorsal root ganglion neurons. J Pharmacol Exp Ther 282:1280-1290.

Jiang Z, Rempel J, Li J, Sawchuk MA, Carlin KP, Brownstone RM (1999) Development of L-type calcium channels and a nifedipine-sensitive motor activity in the postnatal mouse spinal cord. Eur J Neurosci 11:3481-3487.

Juvin L, Simmers J, Morin D (2005) Propriospinal circuitry underlying interlimb coordination in mammalian quadrupedal locomotion. J Neurosci 25:6025-6035.

Kiehn O, Kjaerulff O (1998) Distribution of central pattern generators for rhythmic motor outputs in the spinal cord of limbed vertebrates. Ann NY Acad Sci 860:110-129.

Kjaerulff O, Kiehn O (1996) Distribution of networks generating and coordinating locomotor activity in the neonatal rat spinal cord in vitro: a lesion study. J Neurosci 16:5777-5794.

Kudo N, Yamada T (1987) N-methyl-D,L-aspartate-induced locomotor activity in a spinal cord-hindlimb muscle preparation of the newborn rat studied in vitro. Neurosci Lett 75:43-48.

Kullander K, Butt SJ, Lebret JM, Lundfald L, Restrepo CE, Rydstrom A, Klein R, Kiehn O (2003) Role of EphA4 and EphrinB3 in local neuronal circuits that control walking. Science 299:1889-1892.

Kuo JJ, Siddique T, Fu R, Heckman CJ (2005) Increased persistent $\mathrm{Na}(+$ ) current and its effect on excitability in motoneurones cultured from mutant SOD1 mice. J Physiol (Lond) 563:843-854.

Kuo JJ, Lee RH, Zhang L, Heckman CJ (2006) Essential role of the persistent sodium current in spike initiation during slowly rising inputs in mouse spinal neurones. J Physiol (Lond) 574:819-834.

Lafreniere-Roula M, McCrea DA (2005) Deletions of rhythmic motoneuron activity during fictive locomotion and scratch provide clues to the organization of the mammalian central pattern generator. J Neurophysiol 94:1120-1132.

Lanuza GM, Gosgnach S, Pierani A, Jessell TM, Goulding M (2004) Genetic identification of spinal interneurons that coordinate left-right locomotor activity necessary for walking movements. Neuron 42:375-386.

Marder E, Calabrese RL (1996) Principles of rhythmic motor pattern generation. Physiol Rev 76:687-717.

Miles GB, Dai Y, Brownstone RM (2005) Mechanisms underlying the early phase of spike frequency adaptation in mouse spinal motoneurones. J Physiol (Lond) 566:519-532.

Nishimaru H, Restrepo CE, Kiehn O (2006) Activity of Renshaw cells during locomotor-like rhythmic activity in the isolated spinal cord of neonatal mice. J Neurosci 26:5320-5328.

Paton JF, Abdala AP, Koizumi H, Smith JC, St-John WM (2006) Respiratory rhythm generation during gasping depends on persistent sodium current. Nat Neurosci 9:311-313.

Rybak IA, Shevtsova NA, Lafreniere-Roula M, McCrea DA (2006) Modelling spinal circuitry involved in locomotor pattern generation: insights from deletions during fictive locomotion. J Physiol (Lond) 577:617-639.

Swensen AM, Bean BP (2003) Ionic mechanisms of burst firing in dissociated Purkinje neurons. J Neurosci 23:9650-9663.

Urbani A, Belluzzi O (2000) Riluzole inhibits the persistent sodium current in mammalian CNS neurons. Eur J Neurosci 12:3567-3574.

Van Drongelen W, Koch H, Elsen FP, Lee HC, Mrejeru A, Doren E, Marcuccilli CJ, Hereld M, Stevens RL, Ramirez JM (2006) Role of persistent sodium current in bursting activity of mouse neocortical networks in vitro. J Neurophysiol 96:2564-2577. 
Wang D, Grillner S, Wallen P (2006) Effects of flufenamic acid on fictive locomotion, plateau potentials, calcium channels and NMDA receptors in the lamprey spinal cord. Neuropharmacology 51:1038-1046.

Whelan P, Bonnot A, O’Donovan MJ (2000) Properties of rhythmic activity generated by the isolated spinal cord of the neonatal mouse. J Neurophysiol 84:2821-2833.

Wilson JM, Hartley R, Maxwell DJ, Todd AJ, Lieberam I, Kaltschmidt JA, Yoshida Y, Jessell TM, Brownstone RM (2005) Conditional rhythmicity of ventral spinal interneurons defined by expression of the Hb9 homeodomain protein. J Neurosci 25:5710-5719.

Wu N, Enomoto A, Tanaka S, Hsiao CF, Nykamp DQ, Izhikevich E, Chandler SH (2005) Persistent sodium currents in mesencephalic v neurons participate in burst generation and control of membrane excitability. J Neurophysiol 93:2710-2722.

Zar JH (2000) Biostatistical analysis. Englewood Cliffs, NJ: Prentice-Hall.

Zhang Y, Oliva R, Gisselmann G, Hatt H, Guckenheimer J, Harris-Warrick
RM (2003) Overexpression of a hyperpolarization-activated cation current (Ih) channel gene modifies the firing activity of identified motor neurons in a small neural network. J Neurosci 23:9059-9067.

Zhong G, Diaz-Rios M, Harris-Warrick RM (2006a) Serotonin modulates the properties of ascending commissural interneurons in the neonatal mouse spinal cord. J Neurophysiol 95:1545-1555.

Zhong G, Diaz-Rios M, Harris-Warrick RM (2006b) Intrinsic and functional differences among commissural interneurons during fictive locomotion and serotonergic modulation in the neonatal mouse. J Neurosci 26:6509-6517.

Zona C, Siniscalchi A, Mercuri NB, Bernardi G (1998) Riluzole interacts with voltage-activated sodium and potassium currents in cultured rat cortical neurons. Neuroscience 85:931-938.

Zona C, Cavalcanti S, De Sarro G, Siniscalchi A, Marchetti C, Gaetti C, Costa N, Mercuri N, Bernardi G (2002) Kainate-induced currents in rat cortical neurons in culture are modulated by riluzole. Synapse 43:244-251. 